\author{
EESTI NSV TEADUSTE AKADEEMIA TOIMETISED, 32. KOIDE \\ FOOSIKA * MATEMAATIKA, 1983, NR, 1 \\ ИЗВЕСТИЯ АКАДЕМИИ НАУК ЭСТОНСКОП ССР. ТОМ 32 \\ ФИЗИКА * МАТЕМАТИКА, 1983, № 1
}

А. ВИЛЛ, Т. КЛЕМЕНТИ,

В. МНХКЕЛЬСОО, В. АЛТУХОВ

\title{
ЭЛЕКТРОРАЗРЯДНЫЙ ЭКСИМЕРНЫЙ ИМПУЛЬСНО-ПЕРИОДИЧЕСКИЙ ЛАЗЕР
}

A. VILL, T. KLEMENTI, V. MIHKELSOO, V. ALTUHHOV. ELEKTRILISE ERGASTUSEGA EKSIMEERIMPULSSLASER

4. VILL, T. KLEMENTI, V. MIHKELSOO, V. ALTUHHOV. DISCHARGE-PUMPED HIGH PULSE RATE EXCIMER LASER

\section{(Представил К. К. Ребане)}

Эксимерные лазеры с излучением в УФ-области спектра, в частност: электроразрядные импульсно-периодические лазеры с большой частотой повторения импульсов, отличает простота конструкции, высокая эффективность, большая пиковая мощность и высокая средняя мощность излучения $\left[{ }^{1-5}\right]$, благодаря чему они находят все более широкое научное и практическое применение. Они используются, например, для накачки перестраиваемых лазеров на красителях, высокой очистки веществ в селективной лазерной химии и т. д.

Перед нами стояла цель разработать и экспериментально исследовать компактный эксимерный импульсно-периодический лазер со сравнительно высокой эффективностью и высокой энергией в импульсе, а также подобрать оптимальные параметры системы питания и лазерного излучения путем модельного расчета осциллограмм разрядного тока и напряжения контура.

Электрическая схема эксимерного импульсно-периодического лазера ЭЛИ-2 представляет собой традиционную ТЕА-схему [ $\left.{ }^{6}\right]$ с поперечным продувом рабочего газа между электродами. Генератор Блюмляйна собран на конденсаторах типа КВИ-3, в качестве коммутатора служит тиратрон ТГИ-1-1000/25. Существенно, что параллельно с контуром разряда включены «обостряющие» конденсаторы, позволяющие при оптимальном подборе их емкости повышать кпд более чем в 1,5 раза. Предионизация осуществляется УФ-подсветкой емкостным разрядом через диэлектрик (в данном случае - стекло). Предионизаторы максимально приближены к разрядному объему. Межэлектродное расстояние составляет около 20 мм, длина электродов - 600 мм, радиус кривизны обоих электродов - 20 мм. Использованный способ предионизации обеспечивает однородный емкостный разряд и повышенную диффузность основного разряда. Кроме того, однородность емкостного разряда исключает эрозию электродов, что весьма суще- 


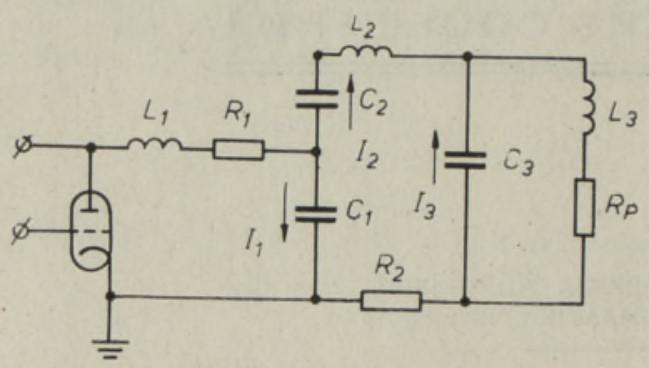

Рис. 1. Эквивалентная электрическая схема системы питания лазера.

ственно для импульсно-периодических лазеров с длительным сроком службы.

Конструктивно лазер выполнен из двух модулей: а) излучателя с балластным объемом и системой порционной смены и дозировки газа и б) блока управления с блоком питания. Последний может обеспечить работу лазера с частотой повторения импульсов до 100 Гц. Для зарядки высоковольтных емкостей используется импульсный трансформатор, в первичную обмотку которого включены накопительные конденсаторы. Коммутатором служит тиристор ТЧИ-100. Продув газа через лазерную кювету обеспечивается тремя параллельными осевыми вентиляторами, вращение которых в рабочем объеме осуществляется с помощью магнитных муфт. Балластный объем.составляет 100 л, кпд блока питания $\sim 70 \%$.

Для расчета осциллограмм тока и напряжения разрядного контура системы питания лазера необходимо было решить систему уравнений Кирхгофа, которую для нашей электроразрядной системы (рис. 1) удобно записать в виде

$$
\begin{aligned}
& I_{1}=F / L_{1}-q_{1} / L_{1} C_{1}-R_{1}\left(I_{1}+I_{2}\right) / L_{1}, \\
& I_{2}=-F / L_{2}, \quad F=R_{2} I_{2}-q_{1} / C_{1}+q_{2} / C_{2}-q_{3} / C_{3}, \\
& I_{3}=F / L_{2}-q_{3} / L_{3} C_{3}-R_{p}\left(I_{2}+I_{3}\right) / L_{3} .
\end{aligned}
$$

Здесь токи $I_{1}, I_{2}, I_{3}$ и на̨чальные условия для зарядов и токов $I_{i}(0)$ $(i=1,2,3)$ при заданном начальном напряжении $V_{0}$ определяются соотношениями

$$
\begin{array}{lll}
I_{1}=\dot{q}_{1}, & I_{1}(0)=0, & q_{1}(0)=C_{1} V_{0}, \\
I_{2}=\dot{q}_{2}, & I_{2}(0)=0, & q_{2}(0)=C_{2} V_{0}, \\
I_{3}=\dot{q}_{3}, & I_{3}(0)=0, & q_{3}(0)=0 .
\end{array}
$$

Значения сопротивления $R_{1}$ и индуктивностей $L_{1}, L_{2}, L_{3}$ контуров разрядной схемы

$$
\begin{array}{ll}
R_{1}=0,1 \text { Ом, } & L_{1}=2 \cdot 10^{-7} \Gamma \mathrm{H}, \\
L_{2}=2 \cdot 10^{-9} \Gamma_{\mathrm{H},} & L_{3}=5 \cdot 10^{-9} \Gamma_{\mathrm{H}}
\end{array}
$$

выбирались исходя из общих конструктивных соображений и предполагаемой средней мощности лазера $(\sim 10 \mathrm{BT})$, а значения других параметров $C_{1}, C_{2}, C_{3}, R_{2}$ и $R_{p}$ подбирались по принципу максимально достижимого кпд и наилучшего совпадения расчетных осциллограмм разряда с экспериментально наблюдаемыми осциллограммами напряжения на «обостряющей» емкости $C_{3}$. Сопротивление плазмы $R_{p}$ аппроксимировалось ступенькой с падением $R_{p}$ до 0,5 Ом в момент пробоя разрядного промежутка примерно через 80 нс после начала коммутации. Качественное и количественное соответствие в поведении расчетных и измеренных осциллограмм (см. рис. 2) указывает на приемлемость использованной нами аппроксимации для $R_{p}(t)$. При выборе значения $C_{3}$ наряду с оптимальным коэффициентом передачи запасенной в конденсаторах энергии в плазму 


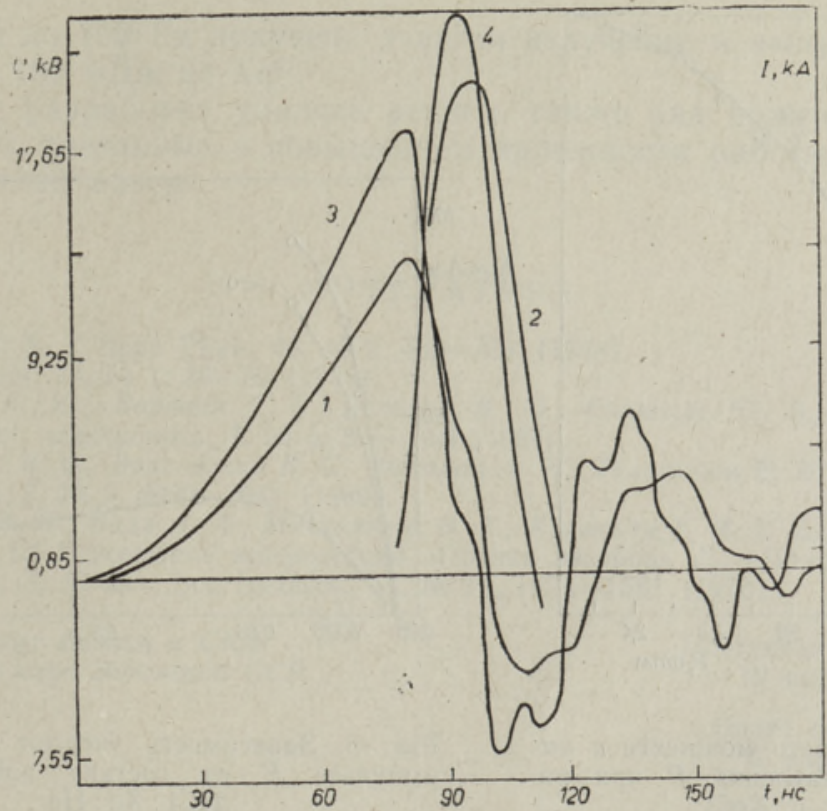

Рис. 2. Временные зависимости разрядного тока $(2,4)$ и напряжения $(1,3)$ : кривые 1 и 2 при $C_{3}=10^{-18}$ Ф, кривые 3 и 4 при $C_{3}=5 \cdot 10^{-9} \Phi$.

$$
K=\varepsilon_{b} / \varepsilon_{0},
$$

где $\varepsilon_{0}=V_{0}^{2}\left(C_{1}+C_{2}\right) / 2, \quad \varepsilon_{b}=\int R_{p}(t) I_{p}(t) d t$, учитывалось условие достижения максимального кпд, ограничивающее величину $C_{3}$ снизу. При этом энерговклад в разряд считался до первого прохождения разрядного тока $I_{p}(t)=I_{2}(t)+I_{3}(t)$ через нуль.

Таким образом были найдены значения $R_{2} \leqslant 0,01$ Ом, $C_{1}=9 \cdot 10^{-9} Ф$, $C_{2}=19 \cdot 10^{-9} \Phi, C_{3}=10 \cdot 10^{-9} \Phi$, обеспечивающие максимальный выход энергии генерации на стандартной рабочей смеси $\mathrm{HCl}: \mathrm{Xe}: \mathrm{He}$ $(0,2: 4: 95,8 \%)$. Варьируя параметры системы питания, удалось подобрать благоприятный режим разряда с достаточно крутым фронтом нарастания напряжения ( 18 кВ за 80 нс) и с коротким $(\sim 20$ нс), но сильным ( 25 кА) импульсом разрядного тока (см. рис. 2). Используя найденные значения $C_{1}$ и $C_{2}$, а также измеренное для этой смеси напряжение пробоя $V_{0}=24 \mathrm{kB}$, получаем для $\mathrm{XeCl-лазера} \mathrm{кпд}$ $\sim 0,9 \%$.

В случае работы на XeF в качестве донора галогена использовался $\mathrm{NF}_{3}$, так как стеклотекстолитовый изолятор разрядной камеры не позволяет работать со фтором. Генерация была получена на смеси $\mathrm{NF}_{3}: \mathrm{Xe}: \mathrm{He}$ $(1: 3: 500)$ при давлении 2,3 атм. Энергия излучения в импульсе при частоте по-

Рис. 3. Зависимость энергии генерации в импульсе $E$ от числа импульсов $N$ при работе на $\mathrm{XeF}$.

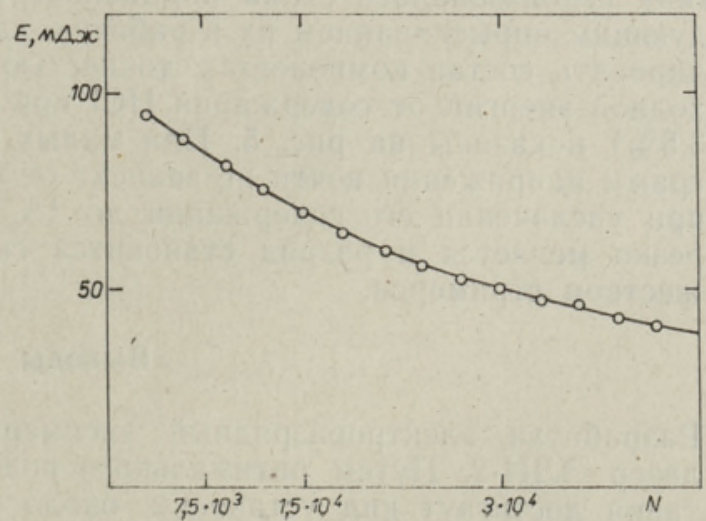




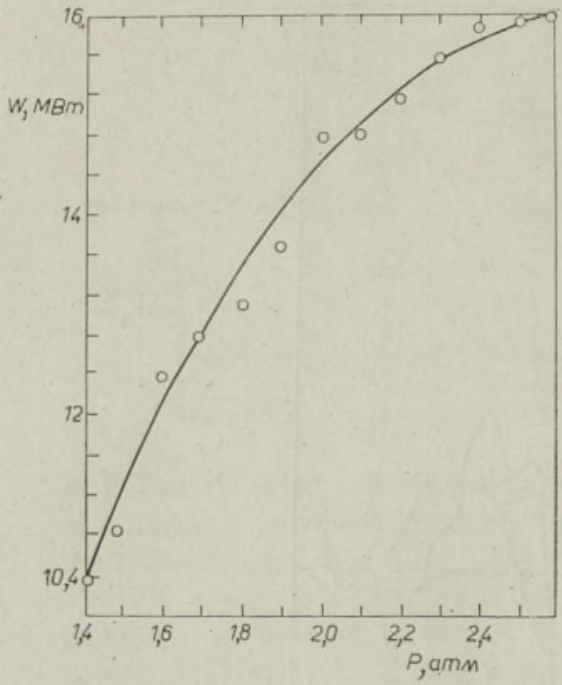

Рис. 4. Зависимость мощности в импульсе $W$ от давления $P$ при работе с $\mathrm{XeCl}$.

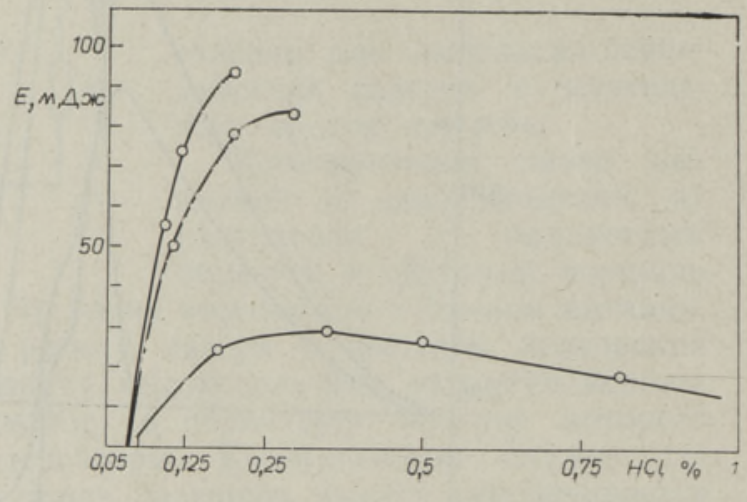

Рис. 5. Зависимость энергии излучения в импульсе $E$ от состава рабочей смеси $\mathrm{HCl}$ : Xe : He.

вторения импульсов до 100 Гц составила 100 мДж, средняя мощность - 10 Вт. K сожалению, срок службы смеси, содержавшей $\mathrm{NF}_{3}$ с доступной нам чистотой $(\sim 96 \%)$, довольно мал и при балластном объеме 100 л исчисляется примерно $3 \cdot 10^{4}$ импульсами (при уменьшении энергии генерации вдвое, рис. 3). При определении ресурса параллельно регистрировались осциллограммы напряжения, вид которых почти не изменялся по мере старения рабочей смеси.

В случае $\mathrm{XeCl}$ для стандартной смеси $\mathrm{HCl}: \mathrm{Xe}: \mathrm{He}$ энергия излучения в импульсе составляет 75 мДж, кпд $\sim 0,9 \%$ и частота повторения импульсов до 100 Гц. Длительность непрерывной работы на ХеCl исчисляется $10^{6}-10^{8}$ импульсами, что значительно дольше, чем на XeF. Форма и длительность импульса генерации регистрировались с помощью ФӘК-29 и стробоскопического осциллографа С7-13. Длительность импульса генерации ХеСl-лазера составляет 15 нс. При снижении давления от 2,6 до 1,4 атм мощность в импульсе на $\mathrm{XeCl}$ уменьшается от 16 до 10,4 МВт (см. рис. 4).

При анализе зависимости выходной энергии от состава рабочего газа использовалась схема порционной дозировки компонент с последующим впрыскиванием их в рабочую камеру. При этом удается регулировать состав компонент с точностью до $0,005 \%$. Зависимости выходной энергии от содержания $\mathrm{HCl}$ при различных дозах $\mathrm{Xe}(0,6 ; 2,3$; $3,5 \%)$ показаны на рис. 5. При малых дозах $\mathrm{HCl}$ характер осциллограмм напряжения почти не зависит от состава рабочей смеси, однако при увеличении его содержания до $1 \%$ форма импульса напряжения резко меняется и разряд становится сильно неустойчивым со множеством стримеров.

\section{Выводы}

Разработан электроразрядный эксимерный импульсно-периодический лазер ЭЛИ-2. Путем оптимального подбора параметров системы питания достигнут кпд установки около $1 \%$. При частоте повторения 
импульсов до 100 Гц получена энергия излучения в импульсе 75 мДж на $\mathrm{XeCl}$ и 100 мДж на XeF.

В ходе разработки удалось решить также ряд инженерно-технических задач, связанных с повышением надежности работы и удобством обслуживания лазера.

\section{ЛИ ТЕР А Т У Р А}

1. Fahlen, T. S. J. Appl. Phys., 49, № 2, 455-457 (1978).

2. Laser Focus, 14, № 1, 28-29 (1978).

3. Баранов В. Ю., Баранов Г. С., Борисов В. М., Кирюхин Ю. Б., Мамонов С. $Г$. Квант. электроника, 7, № 4, 896-898 (1980).

4. Тарасенко В. Ф., Верховский В. С., Федоров А. И., Тельминов Е. Н. Квант, электроника, 7, № 9, 2039-2041 (1980).

5. Алтухов В. И., Вилл А. А., Михкельсоо В. Т., Клементи Т. И. В кн.: Тезисьі докладов III Всесоюзной конференции «Оптика лазеров». Л., «Наука», 1981, с. 105.

6. Laflamme, A. K. Rev. Sci. Instrum., 41, № 11, 1578-1581 (1970).

Ннститут физики и СКБ

Академии наук Эстонской ССР
Поступила в редакцию 12 января 1982

После переработки 2 марта 1982 